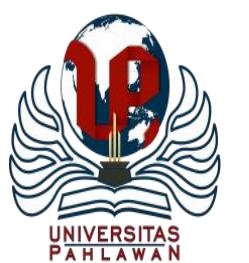

Jurnal Abdidas Volume 2 Nomor 4 Tahun 2021 Halaman 848-858

JURNAL ABDIDAS

http://abdidas.org/index.php/abdidas

\title{
Pelatihan Aplikasi LMS Moodle-Cloud Bagi Guru SMP Muhammadiyah Semanu Kabupaten Gunungkidul
}

\author{
Sigit Widadi $^{1}$, Meilia Safitri ${ }^{2}$ \\ Teknik Elektromedis, Universitas Muhammadiyah Yogyakarta, Indonesia ${ }^{1,2}$ \\ E-mail : swdskom@umy.ac.id ${ }^{1}$ msafitria@gmail.com ${ }^{2}$
}

\begin{abstract}
Abstrak
Pembelajaran daring menjadi metode yang populer pada masa pandemi Covid-19, tetapi banyak lembaga pendidikan yang belum siap melaksanakan metode tersebut termasuk di jenjang pendidikan SMP. Langkah yang paling praktis dan mudah bagi sekolah yang belum siap yaitu menggunakan media sosial dengan berbagai kekurangan yang ada. Pelaksanaan pengabdian kepada masyarakat ini berusaha memberdayakan para guru di SMP Muhammadiyah Semanu Kabupaten Gunungkidul agar mampu menggunakan aplikasi template Learning Management System (LMS) untuk mengatasi kekurangan dalam menyampaikan materi pembelajaran menggunakan media sosial. Metode yang digunakan yaitu pelatihan dan pendampingan bagi para guru. Pelatihan ini memanfaatkan fitur versi trial dari Moodle-Cloud, salah satu situs penyedia layanan sub domain template LMS. Meskipun terdapat kendala teknis di lingkungan siswa, tetapi kegiatan ini berhasil menambah keterampilan guru dalam melakukan manajemen pembelajaran daring. Masih banyak sekolah lain yang perlu bantuan pemberdayaan guru seperti ini, karena belum semua guru di seluruh sekolah pernah belajar menggunakan LMS. Oleh karena itu pengabdian seperti ini sangat diperlukan di masa pandemi agar menjadi salah satu langkah untuk mendukung pelaksanaan pembelajaran jarak jauh (PJJ).
\end{abstract}

Kata kunci: LMS, Moodle-Cloud, SMP Muhammadiyah Semanu

\begin{abstract}
Online learning has become a popular method during the Covid-19 pandemic, but many educational institutions are not ready to implement this method, including at the junior high school level. The most practical and easy step for schools that are not ready is to used social media with various shortcomings. The implementation of this community service seeks to empowered the teachers at SMP Muhammadiyah Semanu, Gunungkidul Regency to be able to used the Learning Management System (LMS) template application to overcome deficiencies in delivering learning materials using social media. The method used is training and mentoring for teachers. This training utilizes the trial version feature of Moodle-Cloud, one of the LMS template sub domain service provider sites. Although there are technical obstacles in the student environment, this activity has succeeded in increasing the skills of teachers in managing online learning. There are still many other schools that need assistance in empowering teachers like this, because not all teachers in all schools have learned to used LMS. Therefore, this kind of service is very much needed during the pandemic so that it becomes one of the steps to supporting the implementation of distance learning (PJJ).
\end{abstract}

Keywords: LMS, Moodle-Cloud, Muhammadiyah Semanu middle school

Copyright (c) 2021 Sigit Widadi, Meilia Safitri

$\triangle$ Corresponding author

Address : Tegalsari Jatirejo Lendah Kulon Progo

Email : swdskom@umy.ac.id

ISSN 2721- 9224 (Media Cetak)

DOI $\quad:$ https://doi.org/10.31004/abdidas.v2i4.352

ISSN 2721- 9216 (Media Online) 


\section{PENDAHULUAN}

Peningkatan jumlah penderita Covid-19 pada awal tahun 2021 di Indonesia dan Propinsi Daerah Istimewa Yogyakarta (DIY) berdampak pada penundaan pembelajaran tatap muka terbatas yang rencananya akan dilaksanakan pada Semester Genap Tahun 2020/2021. Penundaan berdasarkan perpanjangan status tanggap darurat yang dituangkan dalam Surat Keputusan (SK) Gubernur DIY Nomor 388/KEP/2020 (DIY, 2020). Bagi guru dan siswa kondisi ini perlu disiasati agar penyampaian, penerimaan materi dan evaluasi hasil pembelajaran tetap optimal (Sawsan, 2020).

Bagi sekolah yang pernah menjadi grantees Information and Communication Technology for Enhanced Quality Education Program (Program ICT EQEP) memiliki kemungkinan lebih siap melaksanakan pembelajaran daring karena sekolah memperoleh fasilitas infrastruktur dari pelaksanaan program tersebut dan para guru telah mendapatkan pelatihan pembuatan, penggunaan dan administrasi materi pembelajaran menggunakan sarana teknologi informasi dan komunikasi (TIK)(Destiana \& Soenarto, 2014). Program ICT EQEP adalah program kerjasama dalam bentuk konsorsium antara JICA Foundation Japan, Kementerian Komunikasi dan Informatika (Kominfo) dan Pemerintah Propinsi DIY melalui Dinas
Pendidikan Pemuda dan Olahraga (Dikpora) dalam wujud konsorsium pada tahun 2010 hingga tahun 2012. Hanya 500 sekolah jenjang SD dan SMP yang terpilih menjadi pilot project Program ICT EQEP berdasarkan tingkat kesiapan sekolah dari berbagai aspek untuk menerima program tersebut(W. S. Nugroho et al., 2015). Program tersebut dinilai berpengaruh positif terhadap pembelajaran berbasis TIK di sekolah penerima termasuk pemanfaatan Learning Management System (LMS) yang dikelola oleh Balai Teknologi Komunikasi Pendidikan (BTKP) Yogyakarta (H. A. Nugroho et al., 2015).

Berdasarkan pengalaman pengabdi yang menjadi salah satu anggota tim fasilitator pada program tersebut, ICT EQEP mampu membuka wawasan para guru bahwa TIK bukan hanya sebagai salah satu obyek pembelajaran, tetapi TIK dapat dijadikan sebagai basis media pembelajaran. Para siswa tidak hanya belajar TIK tetapi memanfaatkan TIK untuk media belajar pelajaran non TIK.

Bagi sekolah yang para gurunya belum pernah mendapatkan pelatihan LMS dan tidak memiliki infrastruktur yang cukup maka akan mengalami kendala pada saat melakukan manajemen materi dan proses pembelajaran secara daring (Taradisa et al., 2020). Pada sisi lainnya pandemi Covid-19 menyebabkan perubahan metode pembelajaran secara mendadak, sehingga penggunaan media sosial 
dianggap praktis dan dapat digunakan untuk media komunikasi guru dan siswa (Nadeak, 2020).

Cara menggunakan media sosial sangat mudah sehingga menjadi pilihan bagi guru dan siswa. Anggapan ini disebabkan karena media sosial merupakan fasilitas komunikasi yang bersifat umum dan dapat dijalankan di berbagai jenis perangkat komunikasi (Gikasa \& M.Grant, 2013). Meskipun demikian, untuk melakukan pembelajaran, penggunaan media sosial tentu memiliki banyak kelemahan sehingga menimbulkan kesulitan bagi guru (Abbas et al., 2019).

Kesulitan yang sama dialami oleh para guru yang menggunakan media sosial untuk media pembelajaran formal secara daring di SMP Muhammadiyah Semanu. Kesulitan yang paling dirasakan yaitu untuk melakukan manajemen materi pembelajaran agar siswa mudah mengakses kembali materi yang telah disampaikan melalui perangkat smartphone. Tetapi untuk menggunakan perangkat TIK secara ideal sesuai kebutuhan guru dan siswa pada saat ini masih terdapat banyak kendala, terutama kendala di bidang kompetensi guru dalam bidang TIK khususnya pemanfaatan LMS dan kendala infrastruktur ICT.

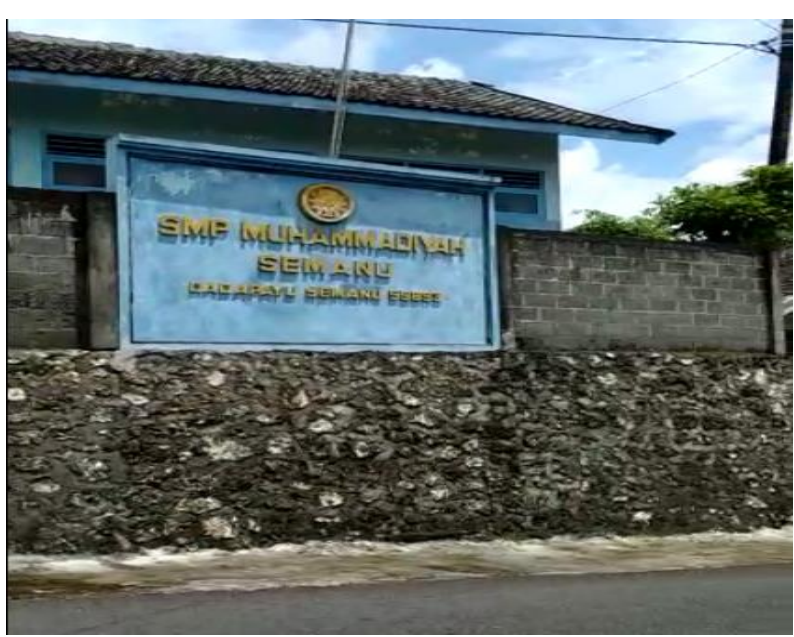

Gambar 1. SMP Muhammadiyah Semanu Gunungkidul

Selain infrastruktur ICT, penggunaan LMS memerlukan transfer of knowledge bagi para guru dan siswa karena terdapat fitur yang cukup kompleks di dalamnya (Sumardi \& Supriawan, 2011). Jika sekolah hendak mengimplementasikan LMS dan dikelola secara mandiri tentu membutuhkan biaya yang tidak murah dan memerlukan sumberdaya manusia yang memiliki kompetensi bidang teknologi informasi untuk melakukan instalasi dan konfigurasi sistem (Alifiyanti \& Ramadoan, 2018).

Bagi sekolah yang masih memiliki keterbatasan kemampuan dalam memanfaatkan aplikasi dan teknologi pendidikan perlu diberikan pelatihan dan pendampingan agar mampu menggunakan LMS dengan fitur sesuai kebutuhan (Maheshwari, 2020). Selain sebagai solusi media proses pembelajaran pada masa pandemi Covid-19, pemanfaatan LMS 
merupakan upaya menumbuhkan budaya penggunaan teknologi informasi dan komunikasi dalam dunia pendidikan (Budiman, 2017). Dalam ruang lingkup persyarikatan langkah tersebut merupakan usaha untuk meningkatkan kualitas amal usaha muhammadiyah (Purba \& Ponirin, 2013).

Bagi siswa di wilayah terpencil dan terdapat kendala geografis untuk memperoleh akses jaringan internet cepat maka penggunaan LMS sebagai media pembelajaran tetap perlu didukung dengan pemanfaatan aplikasi media sosial dan situs untuk berbagi video dan informasi, misalnya Whatsapp Group dan Youtube (Zainuddin \& Keumala, 2018). Kondisi wilayah tersebut serupa dengan kondisi domisili siswa SMP Muhammadiyah Semanu. Bagi sekolah ini, untuk memiliki atau menyewa server LMS tentu menjadi beban berat karena sekolah ini sedang dalam masa perkembangan dengan jumlah siswa sebanyak 51 orang.

Berdasarkan hasil observasi di lokasi pengabdian, diperoleh informasi bahwa dari seluruh guru di SMP Muhammadiyah Semanu yang berjumlah 15 orang, belum ada yang pernah belajar menggunakan aplikasi LMS. Dengan adanya kegiatan ini diharapkan para guru memiliki kemampuan menggunakan LMS untuk mengelola materi dan proses pembelajaran berbasis TIK terutama selama kondisi tanggap darurat pandemi Covid-19 masih diperpanjang oleh pemerintah. Sebab perpanjangan masa tanggap darurat menyebabkan kegiatan belajar mengajar secara tatap muka digantikan dengan pembelajaran secara daring.

\section{METODE}

Metode yang digunakan dalam pengabdian ini yaitu pelatihan dan pendampingan penggunaan LMS. Pelaksanaan pengabdian menggunakan beberapa langkah seperti yang dapat dilihat pada Gambar 2.

Observasi awal merupakan tahap untuk memperoleh data kondisi sekolah dari aspek: a) proses pembelajaran pada masa pandemi Covid-19; b) ijin dari pihak sekolah menjadi mitra pengabdian; c) kesediaan para guru untuk menjadi peserta kegiatan pengabdian.

Setelah diperoleh ijin dari pihak sekolah dan kesediaan para guru selanjutnya dilakukan observasi lanjutan untuk memperoleh data yang lebih lengkap tentang kompetensi para guru dalam bidang TIK, berkas materi pembelajaran yang dimiliki oleh para guru dan ketersediaan perangkat TIK untuk kegiatan pelatihan. 


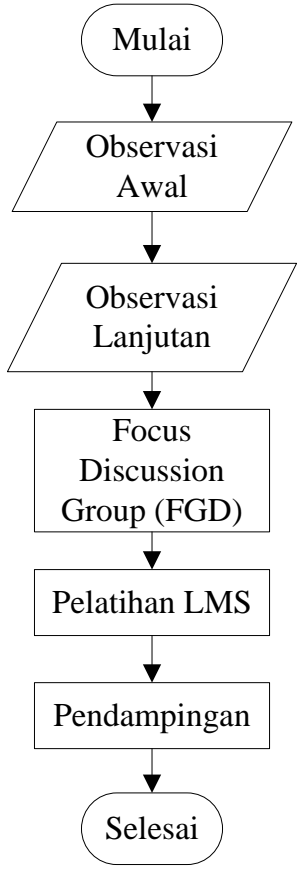

Gambar 2. Diagram Tahap Pelaksanaan

Setelah diperoleh data situasi sekolah dan guru selanjutnya dilakukan focus discussion group (FGD) untuk memperoleh pendalaman masalah yang dihadapi oleh para guru dalam melaksanakan pembelajaran daring.

Pelatihan LMS dilaksanakan dengan metode kombinasi teori, demontrasi dan praktik. Pada tahap ini akan dilakukan upaya menyamakan interpretasi tugas pokok dan fungsi antara ruang lingkup proses pembelajaran dan lingkungan kerja LMS. Kegiatan praktik dibimbing langsung oleh tim pengabdi menggunakan modul panduan praktik.

Pendampingan pemanfaatan LMS dilaksanakan dengan metode konsultatif menggunakan grup media sosial. Langkah ini dimaksudkan untuk memberikan layanan pasca pelatihan apabila peserta mendapatkan kesulitan dalam menggunakan LMS. Pendampingan dilakukan oleh tim pengabdi selama dua bulan jika pihak mitra bermaksud mengimplementasikan aplikasi LMS.

\section{HASIL DAN PEMBAHASAN}

Berdasarkan hasil observasi awal diperoleh informasi bahwa sejak proses pembelajaran tatap muka di SMP Muhammadiyah Semanu terkendala oleh pandemi Covid-19, para guru melakukan penyampaian materi ajar menggunakan media sosial. Setelah mendengarkan penjelasan ringkas tentang rencana tim pengabdi untuk melaksanakan kegiatan tersebut, kepala sekolah mengijinkan dan sangat berharap kegiatan itu dapat segera terlaksana.

Dari langkah observasi lanjutan diperoleh informasi bahwa setiap guru telah memiliki perangkat TIK berupa smartphone, notebook atau laptop dan memiliki alamat surat elektronik yang masih aktif. Diketahui pula bahwa seluruh guru telah mampu mengeksplorasi informasi melalui browser. Dari 15 orang guru belum ada yang pernah mempelajari LMS.

Dari pelaksanaan FGD diketahui bahwa terkait dengan proses pembelajaran seluruh guru menghadapi masalah yang hampir sama, yaitu: a) materi yang disampaikan 
menggunakan media sosial tidak mudah diorganisir menggunakan aplikasi media sosial; b) kecenderungan siswa abai dalam mengakses materi ajar melalui media sosial; c) sistem kontrol yang sulit dilakukan kepada siswa saat sesi pembelajaran daring dilangsungkan; d) pengarsipan berkas pengerjaan tugas dan ujian yang diunggah oleh siswa.

Prioritas penyelesaian masalah yang disepakati dalam FGD tersebut yaitu: a) memuat materi pembelajaran ke dalam LMS agar mudah dicari kembali untuk dipelajari ulang; b) media sosial tetap digunakan sebagai media komunikasi dan informasi tentang proses pembelajaran; c) pelatihan menggunakan aplikasi LMS yang versi gratis sebelum aplikasi sejenis benar-benar diimplementasikan; d) pelatihan mencakup administrasi konten, pemanfaatan fitur aktifitas dan sumberdaya pembelajaran.

Pelaksanaan pelatihan dilakukan pada tanggal 25 Februari tahun 2021, menggunakan ruang rapat di SMP Muhammadiyah Semanu. Kegiatan diikuti oleh 15 orang guru dan berlangsung selama delapan jam. Pelaksanaan pelatihan dibagi dalam tiga sesi. Gambar 3 adalah foto kegiatan yang diambil dari salah satu sudut ruang pelaksanaan.

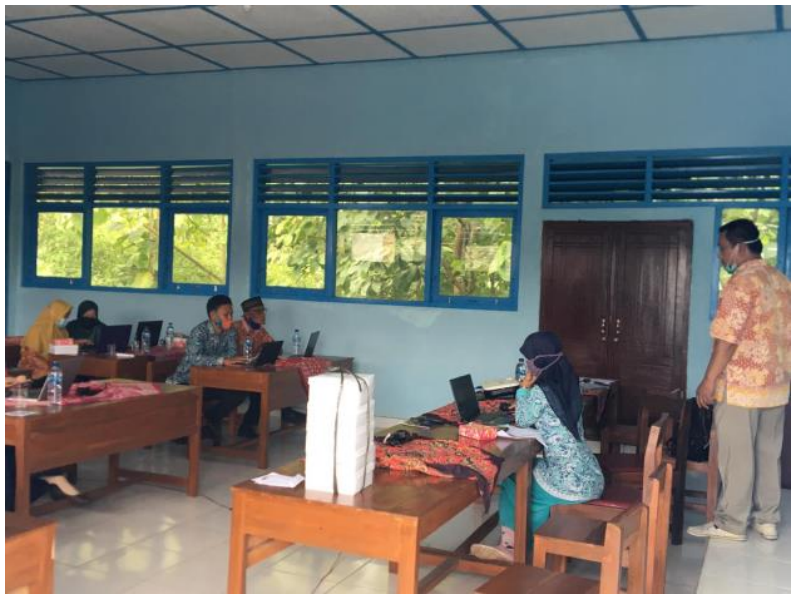

Gambar 3. Pelaksanaan Kegiatan

Sesi pertama yaitu penjelasan tentang cara untuk mengembangkan LMS, cara mendapatkan aplikasi LMS yang sudah siap pakai versi berbayar maupun yang versi gratis dan penjelasan tentang lingkungan kerja LMS. Sesi kedua yaitu demonstrasi penggunaan aplikasi yang telah disiapkan dengan konfigurasi dan konten pembelajaran kemudian dilanjutkan dengan pelatihan teknis aplikasi LMS. Pada sesi ketiga peserta diberikan waktu untuk mencoba simulasi pembelajaran LMS bersama peserta lainnya.

Penjelasan pada sesi pertama bertujuan memberi wawasan bahwa selain menggunakan aplikasi LMS siap pakai di internet, aplikasi tersebut dapat diinstal dan digunakan dalam jaringan komputer lokal di lingkungan sekolah saja dan tidak menggunakan internet. Penggunaan aplikasi LMS hanya di lingkungan sekolah tentu dapat dilaksanakan apabila sudah memungkinkan dilakukan 
pembelajaran tatap muka. Penjelasan tentang lingkungan kerja LMS bertujuan agar peserta dapat menginterpretasikan beberapa istilah dalam lingkungan kerja LMS sesuai dengan istilah yang digunakan dalam ruang lingkup lembaga pendidikan.

Peserta diberikan penjelasan bahwa lingkungan kerja LMS ada tiga tingkatan sesuai kewenangan pengguna, yaitu lingkup admin, instruktur dan siswa. Lingkup admin dapat diasosiasikan sebagai ruang lingkup kerja kepala sekolah, instruktur sebagai ruang lingkup guru dan studen sebagai ruang lingkup siswa. Gambar 4 di bawah ini adalah ilustrasi yang digunakan untuk menjelaskan ruang lingkup LMS kepada peserta.

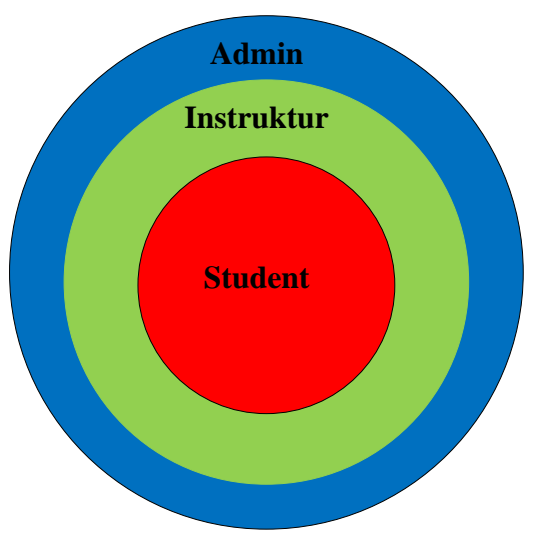

Gambar 4. Ilustrasi ruang lingkup LMS

Pelaksanaan sesi kedua diawali dengan mendemonstrasikan hasil konfigurasi LMS. Aplikasi yang digunakan yaitu template Moodle-Cloud versi trial dengan masa aktif 45 hari. Aplikasi ini telah disunting dan dikonfigurasi oleh tim pengabdi sebelum didemonstrasikan.

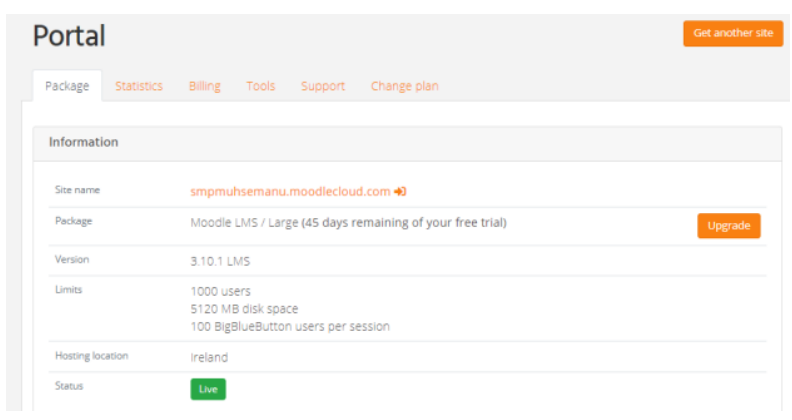

Gambar 5. Fasilitas Moodle-Cloud versi free trial

Demonstrasi ini bertujuan memberikan gambaran kepada peserta tentang wujud hasil penyuntingan dan konfigurasi LMS, sekaligus untuk memicu rasa ingin tahu para peserta agar lebih antusias mengikuti pelatihan. Salah satu halaman yang didemonstrasikan yaitu halaman admin untuk menyunting seluruh bagian LMS, seperti yang ditunjukkan pada Gambar 6.

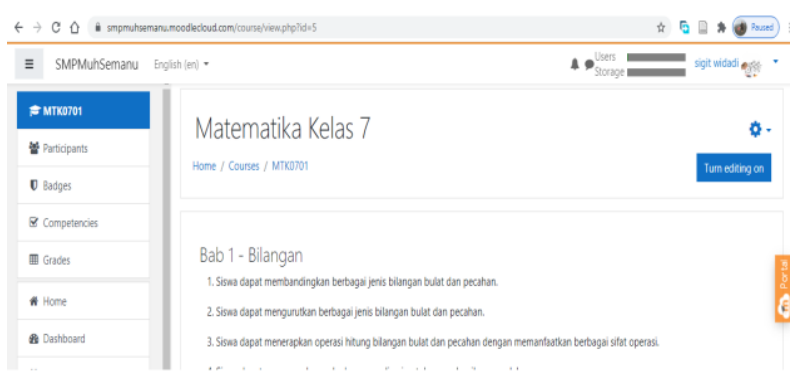

Gambar 6. Demonstrasi Halaman Admin LMS

Tahap selanjutnya yaitu peserta mencoba menyunting template LMS menggunakan aplikasi Moodle-Cloud melalui 
URL moodlecloud.com, melakukan registrasi akun sebagai admin, menyunting berbagai konfigurasi di dalam fitur aplikasi, melakukan administrasi rencana aktifitas dan sumberdaya pembelajaran dan administrasi akun instruktur dan akun student. Halaman untuk pilihan fitur aktifitas dan sumberdaya terlihat seperti pada Gambar 7.

Langkah berikutnya peserta mencoba log in menggunakan salah satu akun instruktur yang dimasukkan melalui lingkup admin, melakukan administrasi pengguna pada tingkat student dan menyunting konfigurasi konten pembelajaran yang akan diakses oleh student. Agar peserta mengetahui bagaimana tampilan aplikasi pada sisi student, maka peserta diminta mencoba $\log$ in menggunakan akun pengguna student.

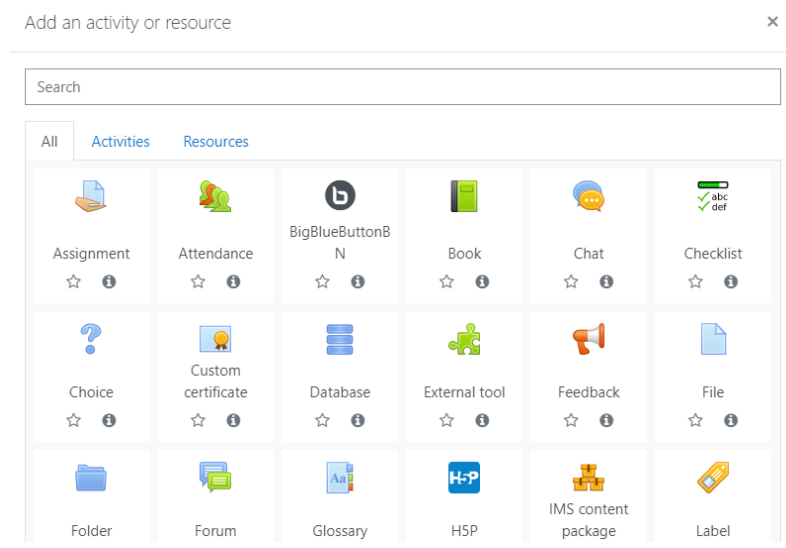

Gambar 7. Halaman Pilihan Fitur Activities Dan Resources Pada Aplikasi Moodle-Cloud

Sesi ketiga yaitu simulasi pemanfaatan aplikasi. Ada peserta yang berperan sebagai admin, instruktur dan peserta lainnya berperan sebagai student. Peserta melakukan peran secara bergantian. Tujuan dari kegiatan sesi ini agar peserta mampu mengamati perubahan yang terjadi pada halaman aplikasi jika pemain peran yang lain melakukan aktivitas di aplikasi. Sesi ketiga dari pelaksanaan kegiatan pelatihan ditutup dengan mengisi kuesioner tentang kendala yang dialami oleh peserta. Hasil yang diperoleh dari kuesioner ditunjukkan pada Tabel 1.

Tabel 1. Kendala yang Pelatihan Aplikasi LMS

\begin{tabular}{|l|l|}
\hline Kendala Belajar Aplikasi LMS & $\begin{array}{l}\text { Jumlah } \\
\text { (orang) }\end{array}$ \\
\hline $\begin{array}{l}\text { Kesulitan memahami cara kerja } \\
\text { aplikasi LMS }\end{array}$ & 2 \\
\hline $\begin{array}{l}\text { Kesulitan memahami bahasa dan } \\
\text { istilah dalam aplikasi }\end{array}$ & 5 \\
\hline $\begin{array}{l}\text { Belum menyiapkan konten } \\
\text { pembelajaran yang siap diunggah ke } \\
\text { portal LMS }\end{array}$ & 12 \\
\hline Sesi latihan terlalu singkat & 10 \\
\hline Kendala teknis lainnya & 8 \\
\hline
\end{tabular}

Kegiatan pendampingan dilakukan oleh tim pengabdi sejak awal bulan Maret hingga akhir bulan April 2021. Pada masa pendampingan ini pihak sekolah mengupgrade aplikasi dari versi trial ke versi berbayar sesuai fitur kapasitas pengguna yang dibutuhkan. Pendampingan dilakukan untuk memberikan layanan konsultasi teknis dan non teknis terkait pemanfaatan aplikasi LMS oleh guru dan siswa. Pada fase ini, secara kolektif peserta kegiatan diminta oleh tim pengabdi agar menyusun modul panduan pemanfaatan 
aplikasi bagi siswa untuk mengakses konten pembelajaran. Diharapkan, dengan menyusun modul panduan tersebut para peserta kegiatan akan lebih mendalami cara penggunaan Moodle-Cloud.

Berdasarkan hasil monitoring tim pengabdi pada masa pendampingan, diperoleh informasi tentang respon para siswa yang disampaikan kepada guru. Respon tersebut diringkas dalam beberapa poin berikut ini.

1. Tampilan aplikasi yang ditampilkan di perangkat komunikasi siswa ada perbedaan tata letak menu dengan tampilan yang ada di komputer guru.

2. Bahasa dalam aplikasi tidak sepenuhnya berbahasa Indonesia, meskipun telah diatur mode bahasa aplikasi dalam bahasa indonesia.

3. Siswa tetap membutuhkan penjelasan melalui media sosial dalam mode audio visual untuk memahami materi pembelajaran di aplikasi LMS.

\section{SIMPULAN}

Setelah kegiatan pengabdian kepada masyarakat selesai dilaksanakan, dapat diambil beberapa kesimpulan, yaitu :

1. Pelatihan penyuntingan dan konfigurasi template LMS perlu didahului dengan pelatihan membuat konten materi pembelajaran.
2. Penggunaan media sosial tetap dibutuhkan oleh guru dan siswa dalam berinteraksi dan berkomunikasi terkait pemanfaatan aplikasi LMS.

3. Panduan pemanfaatan aplikasi LMS untuk mengakses materi pembelajaran perlu disesuaikan dengan beberapa jenis perangkat TIK yang digunakan oleh siswa.

\section{UCAPAN TERIMA KASIH}

Pengabdian kepada masyarakat ini merupakan salah satu skema pelaksanaan Tri Dharma Perguruan Tinggi yang dilaksanakan oleh civitas akademika Fakultas Vokasi Universitas Muhammadiyah Yogyakarta. Materi ini dipilih berdasarkan kebutuhan para guru dan siswa di SMP Muhammadiyah Semanu Gunungkidul pada masa pandemi Covid-19 yang menyebabkan proses pembelajaran harus menggunakan metode Pembelajaran Jarak Jauh (PJJ).

Terselenggaranya kegiatan ini berkat bantuan dan dukungan dari banyak pihak, antara lain :

1. LP3M Universitas Muhammadiyah Yogyakarta yang telah mendanai kegiatan ini.

2. Dekan Fakultas Vokasi Universitas Muhammadiyah Yogyakarta yang telah memfasilitasi kegiatan ini. 
3. BAPPEDA Kabupaten Gunungkidul yang telah memberikan ijin pelaksanaan di lokasi pengabdian.

4. Pimpinan Daerah Muhammadiyah Kabupaten Gunungkidul dan Pimpinan Cabang Muhammadiyah Semanu yang telah mengijinkan pelaksanaan pengabdian di amal usaha milik muhammadiyah.

5. Kepala Sekolah SMP Muhammadiyah Semanu yang telah memberi ijin, memfasilitasi dan membantu koordinasi pelaksanaan kegiatan ini.

6. Mahasiswa KKN Kelompok 09 Semester Gasal 2020/2021 yang telah memberikan bantuan teknis pelaksanaan kegiatan.

Akhir kata, semoga semua pihak yang telah membantu kegiatan ini mendapatkan balasan amal kebaikan dari Allah SWT.

\section{DAFTAR PUSTAKA}

Abbas, J., Aman, J., \& Bano, M. N. S. (2019). The Impact of Social Media on Learning Behavior for Sustainable Education: Evidence of Students from Selected Universities in Pakistan. MDPI, 11, 123.

Alifiyanti, ntan F., \& Ramadoan, F. H. A. N. (2018). Pemanfaatan Learning Management System (LMS) Berbasis Edmodo Materi Fluida Dinamis Untuk Peningkatan Minat Dan Prestasi Belajar Fisika Siswa Sekolah Menengah. Seminar Nasional Fisika Dan Aplikasinya, 155163.

Budiman, H. (2017). Peran Teknologi
Informasi Dan Komunikasi Dalam Pendidikan. Jurnal Pendidikan Islam, $8(1)$.

Destiana, B., \& Soenarto. (2014). Faktor determinan pemanfaatan tik dan pengaruhnya terhadap kinerja guru SMK di Kabupaten Gunungkidul. Jurnal Pendidikan Vokasi, 4.

DIY, P. P. (2020). Surat Keputusan (SK) Gubernur DIY Nomor 388/KEP/2020.

Gikasa, J., \& M.Grant, M. (2013). Mobile computing devices in higher education: Student perspectives on learning with cellphones, smartphones \& social media. ScienceDirect, 19, 18-26.

Maheshwari, P. Das. (2020). Why Schools And Colleges In India Need To Embrace LMS Technology For Future-proofing Education? BWEducation. http://bweducation.businessworld.in/artic le/Why-Schools-And-Colleges-In-IndiaNeed-To-Embrace-LMS-TechnologyFor-Future-proofing-Education-/14-092020-320197/

Nadeak, B. (2020). The Effectiveness of Distance Learning Using Social Media during the Pandemic Period of COVID19: A Case in Universitas Kristen Indonesia. International Journal of Advanced Science and Technology, 29(7), 1764-1773.

Nugroho, H. A., Santosa, P. I., \& Nugroho, W. S. (2015). Analisis Critical Success Factors Penyelenggaraan Layanan ELearning Berbasis Framework ELearning Maturity Model (Kasus: ELearning Pada Program ICT Eqep Di DIY). In JTETI.

Nugroho, W. S., Santosa, P. I., \& Nugroho, H. A. (2015). Identifikasi Critical Success Factors Layanan E-Learning Berbasis Kerangka Kerja E-Learning Maturity Model (Studi Kasus: Program Ict EQEP 
858 Pelatihan Aplikasi LMS Moodle-Cloud Bagi Guru SMP Muhammadiyah Semanu Kabupaten Gunungkidul - Sigit Widadi, Meilia Safitri

DOI: https://doi.org/10.31004/abdidas.v2i4.352

Di DIY). Seminar Nasional Teknologi

Informasi Dan Multimedia, 31-32.

Purba, I. A., \& Ponirin. (2013). Perkembangan Amal Usaha Organisasi Muhammadiyah di Bidang Pendidikan dan Kesehatan. Jurnal Ilmu Pemerintahan Dan SosialPolitik UMA, 1(2), 100-111.

Sawsan, A. (2020). Barriers to distance learning during the COVID-19 outbreak: A qualitative review from parents' perspective. ScienceDirect, 6(11), 1-5.

Sumardi, K., \& Supriawan, D. (2011). Model Pembelajaran E-Learning (LMS) Untuk Meningkatkan Pemahaman Materi Termodinamika Teknik. Ejournal, 7(1), 53-68.

Taradisa, N., Jarnita, N., \& Emalfida. (2020). Kendala Yang Dihadapi Guru Mengajar Daring Pada Masa Pandemi Covid-19 Di MIN 5 Banda Aceh. UINAR-Raniry Press, 1-11.

Zainuddin, Z., \& Keumala, C. M. (2018). Blended Learning Method Within Indonesian Higher Education Institutions. Jurnal Pendidikan Humaniora, 6(2), 6978. 